\title{
Choline: The Neurocognitive Essential Nutrient of Interest to Obstetricians and Gynecologists
}

\author{
Taylor C. Wallace, PhD, CFS, FACN ${ }^{a, b}$, Jan Krzysztof Blusztajn, $\mathrm{PhD}^{c}$, Marie A., PhD, \\ RD Caudill ${ }^{d}$, Kevin C. Klatt, PhD ${ }^{e}$, and Steven H., MD, PhD Zeisel ${ }^{f}$ \\ ${ }^{a}$ Department of Nutrition and Food Studies, George Mason University, Fairfax, VA, USA; ${ }^{\mathrm{b}}$ Think Healthy \\ Group, Inc, Washington, DC, USA; 'Department of Pathology and Laboratory Medicine, Boston

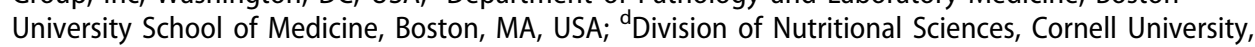 \\ Ithaca, NY, USA; 'USDA/ARS Children's Nutrition Research Center, Baylor College of Medicine, Houston, \\ TX, USA; ${ }^{\prime}$ Research Institute, University of North Carolina, Kannapolis, NC, USA
}

\begin{abstract}
Choline is an essential nutrient for proper liver, muscle, and brain functions as well as for lipid metabolism and cellular membrane composition and repair. Humans can produce small amounts of choline via the hepatic phosphatidylethanolamine $\mathrm{N}$-methyltransferase pathway; however, most individuals must consume this vitamin through the diet to prevent deficiency. An individual's dietary requirement for choline is dependent on common genetic variants in genes required for choline, folate, and one-carbon metabolism. Both the American Academy of Pediatrics and American Medical Association have recently reinforced the importance of maternal choline intake during pregnancy and lactation and recognize that failure to provide choline and other key essential nutrients during the first 1,000 days postconception may result in lifelong deficits in brain function despite subsequent nutrient repletion. Given that dietary intake for the majority of the US population, including subpopulations such as pregnant women, women of childbearing age, and vegetarians, falls well below the current adequate intake, there is a need to develop better policies and improve consumer education around the importance of this essential nutrient for human health. This comprehensive expert review summarizes the current scientific evidence on choline and health in relation to interests of obstetricians and gynecologists.
\end{abstract}

\section{KEY MESSAGES}

There is compelling evidence that demonstrates obtaining the current adequate intake (Al) for choline is problematic for the majority of the US population; excessive intakes above the tolerable upper intake level (UL) are absent.

The dietary requirement for choline is dependent on common genetic variants in genes required for choline, folate, and one-carbon metabolism. Continuing education is needed for health professionals on the importance of choline-rich foods in the diet. Choline must be integrated into the prenatal supplement regimen.

Research suggests not achieving the $\mathrm{Al}$ is likely detrimental to cognitive function in the developing fetus and infant. Adverse neurological consequences due to suboptimal maternal intakes are likely to be identified in future clinical research.

\section{KEYWORDS}

brain; choline; cognition; dietary guidelines; placenta; shortfall nutrient 


\section{Introduction}

Choline (2-hydroxyethyl-trimethyl-ammonium) is a trimethylated, positively charged, quaternary, saturated amine that is an essential micronutrient with critical structural and regulatory roles in the body (Institute of Medicine 1998). It is a source of methyl groups needed to make the primary methyl donor $S$-adenosylmethionine (SAM), a part of the neurotransmitter acetylcholine, and a major component of the phospholipids that compromise cell membranes (sphingomyelin and phosphatidylcholine), thus contributing to their fluidity and structural integrity (Institute of Medicine 1998). The choline derivative, phosphatidylcholine, is a main constituent of very low-density lipoproteins (VLDLs) and is required for hepatic VLDL secretion and thus the removal of fat from the liver (Institute of Medicine 1998; Yao and Vance 1988). Choline is a precursor for betaine, an important osmolyte in the kidney glomerulus that facilitates water resorption from the kidney tubule (Kempson and Montrose 2004). Humans can endogenously produce small amounts of choline via the hepatic phosphatidylethanolamine $\mathrm{N}$-methyltransferase (PEMT) pathway; however, most people must consume this nutrient exogenously to prevent deficiency (Institute of Medicine 1998). In premenopausal women, the gene for the enzyme catalyzing biosynthesis of endogenous choline is induced by estrogen (Resseguie et al. 2007), and some premenopausal nonpregnant women may have lower than average requirements for dietary choline (Fischer et al. 2007). Genetic polymorphisms can increase the choline requirement (Ganz, Cohen et al. 2017; Ganz, Klatt et al. 2017); almost half of premenopausal women have a gene polymorphism that makes biosynthesis of choline unresponsive to estrogen (Fischer et al. 2007). Thus, these women have a similar choline requirement as men (Zeisel and Caudill 2010).

Choline and esters of choline are ubiquitous in food; however, animal products typically contain higher amounts of choline compared to plant foods. The most common forms of choline in foods are fat-soluble phosphatidylcholine and sphingomyelin, as well as water-soluble phosphocholine, glycerophosphocholine, and free choline (USDA 2008). The bioavailability of free choline appears to be high: studies of cytidine- $5^{\prime}$ diphosphocholine (CDP-choline) show virtually complete absorption of free choline after hydrolysis in the small intestine (Secades and Lorenzo 2006). Pancreatic and mucosal enzymes liberate free choline from about half of the fat-soluble forms and from some water-soluble forms (Hollenbeck 2012). Bioavailability of phosphatidylcholine varies depending on the food source, from about $100 \%$ in soybeans to $24 \%$ in canola meal (Emmert and Baker 1997).

Foods naturally containing choline include chicken liver ( 3 oz: $247 \mathrm{mg}$ ); salmon ( 3 oz: $187 \mathrm{mg}$ ); eggs (1 large egg with yolk: $147 \mathrm{mg}$ ); shiitake mushrooms (1/2 cup: $58 \mathrm{mg}$ ); chicken, broilers or fryers (3 oz: $56 \mathrm{mg}$ ); beef, grass-fed strip steak ( $3 \mathrm{oz:} 55 \mathrm{mg}$ ); wheat germ ( $1 \mathrm{oz}$ toasted: $51 \mathrm{mg}$ ); milk ( $8 \mathrm{oz}: 38 \mathrm{mg}$ ); brussels sprouts (1/2 cup: $32 \mathrm{mg}$ ); and almonds (1 oz: $15 \mathrm{mg})$. Select plant foods such as cruciferous vegetables and certain beans are good sources of choline, contributing approximately $10 \%$ of the daily recommended intake (Zeisel and da Costa 2009). Foods, particularly plant foods, also contain betaine, which cannot be converted to choline but can be used as a methyl donor, thereby sparing some of the choline requirement. In animal models, a minimum $50 \%$ of the dietary requirement of choline is still needed, but the remaining $50 \%$ can be spared 
Table 1. Mean intakes of choline from foods and beverages in the United States, 2011-2014.

\begin{tabular}{|c|c|c|c|c|c|}
\hline Age $(y)$ & Mean intake $(\mathrm{mg} / \mathrm{d})^{\mathrm{a}}$ & $\mathrm{Al}(\mathrm{mg} / \mathrm{d})^{\mathrm{b}}$ & Above $\mathrm{Al}(\%)^{\mathrm{a}}$ & $\mathrm{UL}(\mathrm{mg} / \mathrm{d})^{\mathrm{b}}$ & Above UL (\%) \\
\hline \multicolumn{6}{|l|}{ Males } \\
\hline $1-3$ & $221 \pm 7.6$ & 200 & $61 \pm 4.9$ & 1000 & $0.0 \pm 0.0$ \\
\hline $4-8$ & $242 \pm 4.2$ & 250 & $42 \pm 2.5$ & 1000 & $0.0 \pm 0.0$ \\
\hline $9-13$ & $290 \pm 5.2$ & 375 & $14 \pm 1.8$ & 2000 & $0.0 \pm 0.0$ \\
\hline $14-18$ & $346 \pm 11.1$ & 550 & $5 \pm 2.1$ & 3000 & $0.0 \pm 0.0$ \\
\hline $19-30$ & $412 \pm 7.5$ & 550 & $17 \pm 2.2$ & 3500 & $0.0 \pm 0.0$ \\
\hline $31-50$ & $421 \pm 9.1$ & 550 & $14 \pm 2.5$ & 3500 & $0.0 \pm 0.0$ \\
\hline $51-70$ & $391 \pm 7.8$ & 550 & $10 \pm 1.6$ & 3500 & $0.0 \pm 0.0$ \\
\hline$\geq 71$ & $351 \pm 8.2$ & 550 & $4 \pm 1.1$ & 3500 & $0.0 \pm 0.0$ \\
\hline \multicolumn{6}{|l|}{ Females } \\
\hline $1-3$ & $205 \pm 4.8$ & 200 & $40 \pm 4.1$ & 1000 & $0.0 \pm 0.0$ \\
\hline $4-8$ & $211 \pm 4.7$ & 250 & $20 \pm 3.3$ & 1000 & $0.0 \pm 0.0$ \\
\hline $9-13$ & $231 \pm 7.2$ & 375 & $<3$ & 2000 & $0.0 \pm 0.0$ \\
\hline $14-18$ & $223 \pm 7.9$ & 400 & $<3$ & 3000 & $0.0 \pm 0.0$ \\
\hline $19-30$ & $271 \pm 6.6$ & 425 & $<3$ & 3500 & $0.0 \pm 0.0$ \\
\hline $31-50$ & $280 \pm 5.5$ & 425 & $5 \pm 1.5$ & 3500 & $0.0 \pm 0.0$ \\
\hline $51-70$ & $275 \pm 5.4$ & 425 & $4 \pm 1.0$ & 3500 & $0.0 \pm 0.0$ \\
\hline$\geq 71$ & $253 \pm 6.0$ & 425 & $<3$ & 3500 & $0.0 \pm 0.0$ \\
\hline
\end{tabular}

Al, adequate intake; NHANES, National Health and Nutrition Examination Survey; UL, tolerable upper intake level.

${ }^{a}$ Data source: What We Eat in America, NHANES 2011-2014, individuals aged $\geq 1$ year, excluding breast-fed children and pregnant or lactating females. Provided courtesy of Moshfegh (2018).

${ }^{\mathrm{b}}$ Current gender and life-stage Al as defined by the Institute of Medicine (1998).

by intake of betaine (Craig 2004; Dilger et al. 2007). Choline is available commercially as an ingredient in many fortified foods and dietary supplements as choline bitartrate or choline chloride. The US Food and Drug Administration (2017) has mandated fortification of non-milk-based infant formula to the level present in human breast milk since 1985.

The National Academy of Medicine (NAM; formerly the Institute of Medicine [IOM]) Food and Nutrition Board (FNB) has recognized choline as an essential nutrient since 1998 and established dietary reference intakes (DRIs) for individuals in the United States and Canada (Institute of Medicine 1998) (Table 1). The adequate intake (AI) is 425 and $550 \mathrm{mg} /$ day for women and men, respectively, based on prevention of liver damage. The AI for infants was derived by calculating intake from mature human breast milk (Institute of Medicine 1998; Zeisel and Caudill 2010); however, the colostrum has a much greater concentration of choline. Obtaining the current AI for choline seems to be problematic for the majority of the US population (Wallace and Fulgoni 2016, 2017; Moshfegh 2018); furthermore, adequacy goals for choline cannot currently be achieved using food patterns described by the 2015-2020 Dietary Guidelines for Americans (US Department of Health and Human Services \& US Department of Agriculture 2015). This reinforces the need for public guidance that highlights choline-containing foods and/or dietary supplements to help fill the gap. The American Medical Association recently specified the importance of choline during fetal and infant development by recommending that prenatal vitamins include choline, which is a technical challenge because the inclusion of choline in these formulations would significantly increase their physical size (Berg 2017). Similarly, the American Academy of Pediatrics recently stated that although all nutrients are necessary for brain growth, there are key nutrients such as choline, among others, that support neurodevelopment; failure to provide these key nutrients during the first 1,000 days postconception, a critical period for brain development, may result in lifelong deficits in brain function despite subsequent nutrient 
repletion (Schwarzenberg and Georgieff 2018). Choline requirements are also important to consider from a clinical standpoint; up to $84 \%$ of patients who receive total parenteral nutrition (TPN) have been shown to have low plasma choline, as well as fatty liver and liver damage. Patients who received TPN with $2 \mathrm{~g}$ of choline chloride showed improvements in hepatic steatosis after 4 weeks compared with those who received TPN without choline chloride. Recurrent hepatic steatosis was noted at week 34 (10 weeks after discontinuation of the choline chloride) (Buchman et al. 2001).

\section{Current dietary intakes of choline in the United States}

When the AI for choline was established by the NAM FNB in 1998, it was not known whether there were significant numbers of individuals who were choline deficient; until recently, food composition databases provided little data on the choline content of foods to calculate dietary intakes across the population (Institute of Medicine 1998). In 2004, the US Department of Agriculture (USDA) in collaboration with the University of North Carolina released the USDA Database for the Choline Content of Common Foods. This database was updated in 2008 and can currently be used to estimate the choline content of over 630 food items (US Department of Agriculture 2008). Using this USDA database along with consumption data from the National Health and Nutrition Examination Survey (NHANES), researchers have estimated usual choline intakes in the United States to be just over $300 \mathrm{mg} / \mathrm{d}$ for nonpregnant, nonlactating individuals (Wallace and Fulgoni 2016, 2017; Moshfegh 2018). Only about 10\% of Americans and $8 \%$ of pregnant women currently meet their gender- and life-stage-specific AI for choline (Wallace and Fulgoni 2016, 2017; Moshfegh 2018). Table 1 shows the average usual intakes, as well as the percentage of the US population above the AI and tolerable upper intake level (UL) for choline, grouped by gender and life stage. Young children are more likely to meet the AI for choline, although the DRIs for this population are extrapolated from studies based on body mass in adults and may not be optimal. Premenopausal adult women are the least likely gender and life-stage subpopulation to meet the AI: usual intake of choline in this subpopulation is $319 \pm 6 \mathrm{mg} / \mathrm{d}$, which is only approximately $71 \%$ of the AI. The 25 th percentile in this subpopulation has a usual intake of $254 \pm 11 \mathrm{mg} / \mathrm{d}$, which is roughly $60 \%$ of the AI (Wallace and Fulgoni 2017). Vegetarians have the lowest intakes among the US population, estimated at $192 \pm 7 \mathrm{mg} / \mathrm{d}$ (Wallace 2015); choline intakes have been shown to be driven by egg intake and secondarily protein food intake (i.e., meat, poultry, and seafood) (Wallace and Fulgoni 2017). It should again be noted that choline is a precursor to betaine, another "methyl donor" largely present in plant foods such as wheat bran, beets, and spinach. Higher intakes of betaine may spare some of the potential negative consequences of low choline intake among vegetarian populations. Incorporating one to two eggs per day as a substitution for processed and/or red meat in the USDA Healthy US-Style 2000-Kilocalorie Eating Pattern increases choline intakes to current recommended levels, without altering other essential nutrients, and maintains cholesterol intakes within a safe range for healthy individuals (Wallace and Fulgoni 2017). Dietary supplements provide less than $5 \%$ of dietary choline in relation to recommended intakes since choline salts are bulky and vastly increase the size of the supplemental product (Wallace and 
Fulgoni 2017). Choline status (e.g., plasma choline) is not a reliable indicator of moderate changes in dietary choline intake since it is homeostatically regulated by the body. No optimal method for clinical assessment of choline status exists.

\section{Consequences of deficiency and excess}

\section{Deficiency}

Choline deficiency causes clinical illness in humans. Healthy men and women with normal folate and vitamin $\mathrm{B}_{12}$ status who were fed a choline-deficient diet developed liver damage, characterized by elevated liver enzymes in the blood, as well as muscle damage as indicated by increased circulating creatine phosphokinase $(\mathrm{CK})$ concentrations, which resolved when choline was restored to the diet (Zeisel et al. 1991; da Costa et al. 2004). Phosphatidylcholine is essential for the normal assembly and secretion of VLDLs that transport triacylglycerol (TAG) out of the liver; hepatic steatosis during deficiency results in accumulation of TAG in hepatocytes (Cole et al. 2012), causing release of the liver enzymes alanine aminotransaminase and aspartate aminotransferase into the blood, likely due to loss of phosphatidylcholine from the plasma membrane (Li et al. 2005). The susceptibility to develop liver damage has been shown to be related to polymorphisms of the gene phosphatidylethanolamine $N$-methyltransferase (PEMT) (Song et al. 2005) with loss of estrogen receptor binding, as well as polymorphisms in other enzymes involved in choline metabolism (Resseguie et al. 2007, 2011). Only a portion (44\%) of premenopausal women develop such problems when choline deficient because estrogen induces the PEMT gene and allows for an increase in de novo production of choline (Resseguie et al. 2007).

During pregnancy, estrogen concentrations rise from approximately 1 to $60 \mathrm{nmol} / \mathrm{L}$ at term (Sarda and Gorwill 1976; Adeyemo and Jeyakumar 1993), suggesting that endogenous choline production may be higher during this critical period for fetal development. Despite this potential enhanced capacity to synthesize choline, fetal/infant demand is so high that maternal stores are depleted during pregnancy and lactation in animal models (Zeisel and Caudill 2010), while pregnant women exhibit a marked depletion of choline-derived methyl donors (Yan et al. 2012) secondary to enhanced partitioning of choline toward the CDP-choline pathway (as opposed to betaine synthesis) (Yan et al. 2013) along with greater use of betaine as a methyl donor (Yan et al. 2013). Women with lower choline intakes during pregnancy have been shown to be at greater risk of having an infant with a neural tube defect (NTD) or cleft palate (Shaw et al. 2004, 2006; Carmichael et al. 2010); this may be more frequent in women with the rs7946 G allele of PEMT (Mills et al. 2014). A very common genetic variation in folate metabolism that has been linked to risk of NTDs is the 5,10-methylenetetrahydrofolate dehydrogenase 1958 A (MTHFD1) allele (rs2236225). Premenopausal women carrying this allele have been shown to be 15 times as likely as noncarriers to develop signs of choline deficiency on a low-choline diet (Kohlmeier et al. 2005). It is likely that the variant MTHFD1 gene decreases the availability of the methyltetrahydrofolate, thereby increasing the metabolic use of choline as a methyl donor.

Elevations in markers of DNA damage, as well as alterations in lymphocyte gene expression, are also commonly observed during the deficiency state (da Costa et al. 
2006; Niculescu et al. 2007; Zeisel 2012). DNA methylation can strongly influence gene expression; alterations in DNA methylation have been linked to diseases such as cancer and syndromes involving chromosomal instabilities (Egger et al. 2004). DNA methylation is also responsible for imprinting during the perinatal period, which may influence disease susceptibility later in life (Waterland and Jirtle 2004). It is important to note that lack of dose-response studies and reliance on an AI make it difficult to assess consequences between insufficiency versus deficiency.

\section{Toxicity}

High intakes of choline are associated with a fishy body odor, vomiting, excessive sweating and salivation, hypotension, and liver toxicity. The NAM defined a UL for adults based on a study in seven patients with Alzheimer's disease, where oral administration of $7.5 \mathrm{~g} / \mathrm{d}$ of choline resulted in a hypotensive effect accompanied by nausea and diarrhea (Boyd et al. 1977). Similar gastrointestinal effects and a fishy body odor were observed among participants in studies administering 8-20 g/d (Growdon et al. 1977; Gelenberg et al. 1979; Lawrence et al. 1980). The NAM considered $7.5 \mathrm{~g} / \mathrm{d}$ of choline as the lowest observed adverse effect level; after application of an uncertainty factor of 2 and rounding, the NAM set a UL of $3.5 \mathrm{~g} / \mathrm{d}$ for adults. The NAM FNB was unable to establish ULs for infants due to the lack of data on adverse effects in this age group, and the ULs for children were derived from the adult value by allometric scaling (exponent 0.75) according to reference body weights (Institute of Medicine 1998) (Table 1). The European Food Safety Authority Nutrition Dietetics and Allergies Panel (2016) did not define a UL for choline in 2016.

Consumption has been shown to increase production of trimethylamine $\mathrm{N}$-oxide (TMAO), a gut-derived choline metabolite (naturally abundant in fish), which has recently emerged as a candidate risk factor for heart disease and other adverse health outcomes. One purported mechanism involves microbial production of trimethylamine (TMA) from dietary substrates and its subsequent conversion to TMAO in the liver. Considerable interindividual variations in circulating and urinary TMAO concentrations have been reported in response to egg and supplemental choline. However, the relation between TMAO and chronic disease can be confounded by several factors, including kidney function, the gut microbiome, and flavin-containing monooxygenase 3 (FMO3) genotype. A recent crossover feeding trial in healthy young men consuming meals containing TMAO (fish), its dietary precursors, choline (eggs), and carnitine (beef) versus a fruit control showed that fish consumption, widely known for its cardioprotective attributes, yielded higher circulating and urinary concentrations of TMAO (42-62 times; $p<0.0001$ ) than eggs, beef, or the control (Cho et al. 2017). High TMAO producers ( $\geq 20 \%$ increase in urinary TMAO in response to eggs and beef) were found to have a higher ratio of Firmicutes to Bacteroidetes and a less diverse gut microbiome (Cho et al. 2017); this is consistent with previous reports that suggested trimethylamine production is noted in Firmicutes but not Bacteroidetes (Falony et al. 2015). Notably, a greater ratio of Firmicutes to Bacteroidetes has previously been associated with an increased risk of obesity and metabolic syndrome (Ley et al. 2005). As such, higher circulating concentrations of TMAO in a disease versus a nondisease state may reflect 
Table 2. Summary of the associations between single nucleotide polymorphisms and the odds of developing choline deficiency-associated organ dysfunction (i.e., liver and/or skeletal muscle).

\begin{tabular}{|c|c|c|c|}
\hline Gene & Function & SNP & Choline deficiency risk \\
\hline MTHFR & $\begin{array}{l}\text { Converts 5,10-methyleneTHF } \\
\text { to } 5 \text {-methylTHF; rate-limiting } \\
\text { step in use of folate as } \\
\text { methyl donor }\end{array}$ & $\begin{array}{l}\text { rs1801133 } \\
\text { rs1801131 }\end{array}$ & $\begin{array}{l}\text { Not significant } \\
\text { Not significant }\end{array}$ \\
\hline MTHFD1 & $\begin{array}{l}\text { 10-formyl-, 5,10-methenyl, } \\
\text { and 5,10-methylene-THFs; } \\
\text { SNP resides in the enzymatic } \\
\text { activity associated with } 10- \\
\text { formyl-THF synthesis }\end{array}$ & rs2236225 & $\uparrow$ odds organ dysfunction \\
\hline Reduced-folate carrier (RFC) & $\begin{array}{l}\text { Transports reduced folates } \\
\text { with high affinity at a } \\
\text { physiological pH }\end{array}$ & rs1051266 & Not significant \\
\hline MTR & $\begin{array}{l}\text { Vitamin } \mathrm{B}_{12^{-}} \text {and folate- } \\
\text { dependent conversion of } \\
\text { homocysteine to methionine }\end{array}$ & rs1805087 & Not evaluated \\
\hline MTRR & $\begin{array}{l}\text { Regenerates Metrifonate } \\
\text { (MTF) after oxidation }\end{array}$ & rs1801394 & Not evaluated \\
\hline CHKA & $\begin{array}{l}\text { Phosphorylates choline, first } \\
\text { step in CDP-choline pathway }\end{array}$ & rs10791957 & $\downarrow$ odds organ dysfunction \\
\hline $\mathrm{CHDH}$ & $\begin{array}{l}\text { First step in oxidation of } \\
\text { choline to betaine }\end{array}$ & $\begin{array}{l}\text { rs9001 } \\
\text { rs12676 }\end{array}$ & $\begin{array}{l}\downarrow \text { odds organ dysfunction } \\
\uparrow \text { odds organ dysfunction }\end{array}$ \\
\hline BHMT & $\begin{array}{l}\text { Converts homocysteine to } \\
\text { methionine using betaine as } \\
\text { a methyl donor }\end{array}$ & rs3733890 & Not significant \\
\hline PEMT & $\begin{array}{l}\text { Uses S-adenosylmethionine to } \\
\text { triply methylate } \\
\text { phosphatidylethanolamine to } \\
\text { form phosphatidylcholine } \\
\text { (endogenous } \\
\text { choline synthesis) }\end{array}$ & $\begin{array}{l}\text { rs12325817 } \\
\text { rs4646343 } \\
\text { rs2266782 }\end{array}$ & $\begin{array}{l}\uparrow \text { odds organ dysfunction } \\
\uparrow \text { odds organ dysfunction } \\
\text { Not significant }\end{array}$ \\
\hline SLC44A1 & $\begin{array}{l}\text { Transports choline across the } \\
\text { cellular and } \\
\text { mitochondrial membranes }\end{array}$ & $\begin{array}{l}\text { rs7873937 } \\
\text { rs3199966 }\end{array}$ & $\begin{array}{l}\uparrow \text { odds muscle damage } \\
\uparrow \text { odds muscle damage }\end{array}$ \\
\hline
\end{tabular}

Adapted with permission from Ganz, Klatt, and Caudill (2017a). BHMT, betaine homocysteine S-methyltransferase; CDPcholine, cytidine 5'-diphosphocholine; $C H D H$, choline dehydrogenase; CHKA, choline kinase alpha; MTHFD1, methylenetetrahydrofolate dehydrogenase 1; MTHFR, methylenetetrahydrofolate reductase; MTR, methionine synthase; MTRR, methionine synthase reductase; PEMT, phosphatidylethanolamine N-methyltransferase; SLC44A1, solute carrier family 44 member 1; SNP, single nucleotide polymorphism; THF, tetrahydrofolate.

differences in gut microbe composition rather than indicate a causative role of TMAO in the disease process (Cho et al. 2017).

\section{Genetic variants that alter metabolism and influence dietary requirements for choline}

Nutrient needs vary depending upon a number of modifiable and nonmodifiable factors; current DRIs for nutrients consider the impact of sex, age, and reproductive life stage on nutrient needs. However, additional variation in nutrient needs still remains, and many researchers hypothesize that genetic variants contribute to this variation. For dietary choline, a large and growing body of research has supported the notion that common genetic variants in genes required for choline, folate, and one-carbon metabolism influence dietary choline requirements. Several single nucleotide polymorphisms (SNPs) have been shown to predict the likelihood of developing signs of choline 
deficiency in controlled laboratory settings where dietary choline intake is low, as recently reviewed by Ganz, Cohen et al. (2017) and Ganz, Klatt et al. (2017) (Table 2). These variants also impact the metabolic fate of choline, influencing the relative amount of choline that is used to make phosphatidylcholine through the CDP-choline pathway or oxidized to the methyl donor, betaine.

Several SNPs are worth highlighting for their pronounced impact on the risk of choline inadequacy and metabolic partitioning of choline. These SNPs occur in genes for both folate and choline metabolism, owing to the closely interconnected metabolism of these nutrients and their critical role in methyl metabolism. Choline, through its metabolite, betaine, and folate can serve as sources of methyl donors to convert homocysteine to methionine, which is then used to generate SAM, the universal methyl donor. SAM is used by more than 100 methyltransferase enzymes throughout metabolism. When an individual has low folate status and/or harbors a genetic variant that alters folate metabolism, the metabolic use of choline is altered. Women with variants in genes encoding folate-metabolizing enzymes partition more dietary choline toward phosphatidylcholine biosynthesis via the CDP-choline pathway (at the expense of betaine synthesis), possibly due to impaired phosphatidylcholine biosynthesis via the PEMT pathway, which is dependent on folate-mediated one-carbon metabolism (Ganz et al. 2016). A G $\rightarrow$ A substitution (rs2236225) in the methylenetetrahydrofolate dehydrogenase 1 (MTHFD1) gene has been found to be associated with 7 -fold increased odds of developing organ dysfunction when fed an experimental low-choline diet and no supplemental folic acid; in premenopausal women with this variant consuming the low-choline diet, the odds of developing organ dysfunction were 15-fold higher (Kohlmeier et al. 2005; da Costa et al. 2006; Ganz, Cohen et al. 2017; Ganz, Klatt et al. 2017). MTHFD1 polymorphisms have been shown to lead to higher homocysteine levels during folate restriction, a marker of cardiovascular disease, and reduce the amount of choline that is oxidized to betaine (Ganz et al. 2016). About 15\%-30\% of humans possess genetic polymorphisms that alter the activity of MTHFD1, resulting in a greater requirement for folate and potentially for choline, even when dietary intake of folate is high (Ganz et al. 2016). An additional variant with a substantial impact on choline needs and metabolism is a polymorphism in the promoter region of PEMT $(-744 \mathrm{G} \rightarrow \mathrm{C}$; rs12325817), a gene that encodes the enzyme PEMT, which produces phosphatidylcholine from another phospholipid, phosphatidylethanolamine. This pathway allows the body to make phosphatidylcholine without a direct need for choline (although choline can contribute to this pathway by donating methyl groups to SAM to be used by the PEMT enzyme). Individuals with the PEMT rs12325817 C variant consuming an experimental low-choline diet have been shown to have 25-fold higher odds of developing symptoms of organ dysfunction. Genetic variants in the promoter region of the PEMT gene disrupt the typical upregulation of this gene in response to estrogen, increasing the dependence on dietary choline to meet the need for synthesis of phosphatidylcholine through the CDP-choline pathway (Resseguie et al. 2007). Other PEMT SNPs (rs7946, rs4646343) have also been identified in the promoter region for the PEMT gene and are found to impact circulating homocysteine concentration and the metabolic fate of choline. For other genetic variants in folate and choline metabolism that impact choline needs and metabolism, the reader is referred to the recent review by Ganz, Klatt et al. (2017). 


\section{Dietary choline and placental health}

Increasing evidence has demonstrated that, similar to the developing fetal brain, the placenta is sensitive to choline supply throughout pregnancy. Optimal development and functioning of the placenta are critical for maternal and fetal health, and impairments result in maternal disease, such as preeclampsia, and undesirable fetal outcomes, including intrauterine growth restriction. In a randomized controlled feeding trial with choline intakes of 480 versus $930 \mathrm{mg} /$ day, placentas from third-trimester pregnant women consuming higher amounts of dietary choline exhibited significant changes in the expression of genes regulating placental vascularization and angiogenesis (Jiang, Bar et al. 2012; Jiang, Yan et al. 2012). Of note, higher choline intakes lowered the placental expression and circulating protein levels of soluble fms-like tyrosine kinase-1 (sFLT1), a vascular endothelial growth factor decoy receptor causally implicated in the pathogenesis of preeclampsia. This finding spurred several preclinical investigations into the impact of choline availability and dietary choline supplementation on placenta development and function. In cultured immortalized extravillous trophoblasts, a model of the placental cell type that invades the maternal decidua, lower choline availability induced a proinflammatory, antiangiogenic phenotype (Jiang et al. 2014). These results suggest that choline supply may impair early placental development and arterial remodeling, which is required for placental perfusion and nutrient transfer (Jiang et al. 2014). These effects in cultured cells were largely confirmed in mouse models: higher dietary choline intakes, comparable to the levels shown to improve cognitive outcomes in rodents, beneficially impacted placental markers of inflammation, oxidative stress, and arterial morphology while also modulating nutrient transport across the placenta, including transfer of the critical omega 3 fatty acid, docosahexaenoic acid (Kwan, King, Yan, Jiang et al. 2017; Kwan, King, Yan, Wang et al. 2017); notably, these effects appear to be sex dependent, a finding that requires further consideration in human studies. Choline's effect on placental function may be, in part, mediated through its impact on the placental epigenome. Higher dietary choline intakes in third-trimester pregnant women are associated with global changes in placental DNA and histone methylation and site-specific increases in promoter methylation at the locus for the cortisol-regulating gene, corticotropin-releasing hormone ( $\mathrm{CRH})$; these site-specific changes were associated with reduced placental $\mathrm{CRH}$ transcript abundance and lower fetal cord blood cortisol concentrations (Jiang, Yan et al. 2012). Preliminary investigations in mice have also suggested that higher dietary choline intakes impact global DNA methylation, sitespecific methylation of several imprinted genes, and placental microRNA expression (Kwan et al. 2018).

\section{Higher prenatal choline intake may decrease the risk of neural tube defects}

A small number of human studies have assessed maternal choline intake or status in regard to risk of neurological birth defects in the offspring (reviewed in Wallace 2018). Higher maternal choline intakes, estimated using food frequency questionnaires, in both case-controlled and longitudinal studies, have suggested an inverse relationship with spina bifida (Shaw et al. 2004, 2009; Carmichael et al. 2010; Lavery et al. 2014). The only study to examine maternal plasma total choline concentrations during the first 
prenatal visit found no associations with the development of spina bifida at birth; however, cases of NTDs were significantly more prevalent among offspring whose mothers expressed the G allele of PEMT rs9746 (Mills et al. 2014), consistent with genetic susceptibilities discussed earlier. Elevated NTD risk was associated with the lowest decile of choline intake (odds ratio, 2.4; 95\% confidence interval, 1.3-4.7) and reduced risk was seen in the highest decile of intake (odds ratio, 0.14; 95\% confidence interval, $0.02-1.0$ ) among women in a large California cohort who were sufficient in folate due to folic acid fortification and/or supplementation of the food supply (Shaw et al. 2009). The variance in findings may be suggestive of genetic differences among populations as previously mentioned; a descriptive study found rates of NTDs to be $50 \%-200 \%$ higher among Mexican Americans residing along the Texas-Mexico border as compared to non-Hispanic whites and African Americans in other states such as North Carolina (Hendricks et al. 1999). In rodents, dietary choline is needed for normal neural tube closure in early pregnancy (Fisher et al. 2001, 2002).

\section{Neurocognitive actions of dietary choline}

The mechanisms and clinical evidence in regard to neurodevelopmental and neuroprotective actions of choline were recently extensively reviewed by Blusztajn et al. (2017) and Wallace and Fulgoni (2017). High choline intakes during gestation and early childhood have been shown to enhance cognition across the lifespan in multiple animal models (Blusztajn et al. 2017; Wallace 2018; Zeisel and Caudill 2010) and some shortterm longitudinal human studies (Wallace and Fulgoni 2017). The maternal choline supply in rats during pregnancy modifies fetal DNA methylation (Kovacheva et al. 2007, 2009) and histone methylation (Davison et al. 2009), suggesting a possible epigenetic mechanism for the long-term effects of choline intake seen in animal models and in longitudinal human studies.

\section{Neuroprotective actions of prenatal choline against epilepsy, fetal alcohol syndrome, and inherited conditions}

High choline intake during gestation and early postnatal development in rat and mouse models protects the brain from neurological damage associated with epilepsy (Yang et al. 2000; Holmes et al. 2002; Glenn et al. 2008; Wong-Goodrich et al. 2011), fetal alcohol syndrome (Thomas et al. 2000; Thomas et al. 2007; Ryan et al. 2008; Otero et al. 2012; Thomas and Tran 2012; Schneider and Thomas 2016; Thomas et al. 2007), and inherited conditions such as Down syndrome (Moon et al. 2010; Velazquez et al. 2013; Ash et al. 2014; Kelley et al. 2014, 2016; Strupp et al. 2016; Powers et al. 2017) and Rett syndrome (Nag and Berger-Sweeney 2007; Nag et al. 2008; Ricceri et al. 2011; Ricceri et al. 2013). These effects are correlated with modifications in histone and DNA methylation in the brain, as previously reviewed by Blusztajn et al. (2017). A human intervention study examined supplemental intake of $625 \mathrm{mg} / \mathrm{d}$ choline in children aged 5-10 years with diagnosed fetal alcohol spectrum disorders but failed to find any effect on cognitive outcomes after 6 weeks (Buhusi et al. 2008). A separate randomized controlled trial (RCT) of phosphatidylcholine supplementation conducted in 100 women 
from the second trimester through the third postnatal month observed that a CHRNA7 rs3087454 genotype, associated with schizophrenia, diminished P50 cerebral evoked response inhibition in placebo-treated, but not in choline-treated, infants. This suggests that perinatal choline activates timely development of cerebral inhibition, even in the presence of gene mutations that would otherwise delay it (Ross et al. 2013). Choline supplementation when administered together with routinely recommended multivitamin-multimineral prenatal supplements during pregnancy recently showed beneficial impacts on basic learning mechanisms involved in encoding and memory of environmental events in alcohol-exposed pregnancies as well as in non- or low-alcohol-exposed pregnancies in a prospective study, possibly due to prevention of fetal alcohol-related depletion of dimethylglycine, a metabolic nutrient that can protect against overproduction of glycine, during critical periods of neurogenesis (Coles et al. 2015; Kable et al. 2015).

\section{Prenatal and childhood neurocognitive development}

High choline intake during the perinatal period has been demonstrated to have a lasting neuroprotective effect in both animal and human studies. Caudill et al. (2018) reported effects of human maternal choline supplementation $(480$ or $930 \mathrm{mg} / \mathrm{d}$ ) during the third trimester on infant processing speed and visuospatial memory at 4, 7, 10, and 13 months of age $(n=24)$. This controlled feeding study found that maternal consumption of approximately twice the AI for choline during the third trimester (i.e., 930 versus $480 \mathrm{mg} / \mathrm{d}$ ) improved infant information processing speed. There was also a linear effect of exposure duration (i.e., infants exposed longer showed faster reaction times) in the lower intake group (i.e., $480 \mathrm{mg} / \mathrm{d}$ ), suggesting that even modest increases in prenatal choline intake may produce cognitive benefits in humans (Caudill et al. 2018). To evaluate the persistence of the cognitive benefits observed by Caudill et al. (2018), the Strupp and Canfield laboratory recently conducted a follow-up study of the children in this cohort at 7 years of age. Results of the cognitive assessment revealed lasting benefits of the higher maternal choline intake on child attention, memory, and problem-solving areas of cognition previously shown to be sensitive to maternal choline supplementation (Bahnfleth et al. 2019). Although these findings must be confirmed in a larger sample, they provide compelling evidence that maternal choline intake during pregnancy has lasting effects on a child's cognitive function. An older RCT found null effects of $750 \mathrm{mg} / \mathrm{d}$ choline supplementation (as phosphatidylcholine) from 18 weeks of gestation to 90 days postpartum on infant cognitive function (Cheatham et al. 2012). It is unclear why this study did not observe similar cognitive effects as the study by Caudill et al. (2018); however, poor participant adherence and/or uncontrolled variations in intake of choline and other nutrients have been suggested to play a role (Caudill et al. 2018; Wallace 2018). Data from observational studies are somewhat mixed but tend to also support that higher choline intakes during pregnancy enhance cognitive outcomes of the offspring (Boeke et al. 2013; Signore et al. 2008; Villamor et al. 2012; Wu et al. 2012). Consistent with the findings from the Strupp and Canfield laboratory, data obtained from Project Viva in Massachusetts demonstrated that maternal choline intake within the AI range during pregnancy was associated with better memory function in 
children 7 years of age compared with children of mothers whose consumption was approximately $50 \%$ of the AI (Boeke et al. 2013). A narrative review by McCann et al. (2006) highlighted 34 rodent studies that examined the relationship of choline during early development and suggested that supplementation during pregnancy may strongly contribute to changes in neurological function in the fetus, as well as improvement in postnatal cognitive behavioral tests across the lifespan. In rats, high maternal choline intake at specific times during the pregnancy and lactation periods enhances cognitive ability of the offspring throughout life. There are two sensitive periods in rat brain development during which supplementation with choline produces long-lasting enhancement of spatial memory that is lifelong. The first occurs during embryonic days 12-17 (rats give birth on day 21) and the second during postnatal days 16-30 (Cermak et al. 1999; Loy et al. 1991; Meck and Williams 1997a,b,c, 1999; Pyapali et al. 1998; Williams et al. 1998; Tees 1999a,b; Zeisel 2000). Supplementation during these critical periods elicited a major improvement in memory performance of rats at all stages of training on a 12-arm radial maze (Meck et al. 2007). In rats, the additional choline induced an increase in spatial memory that correlated with changes in the birth, death, and migration of cells in the hippocampus during fetal brain development and with the distribution and morphology of neurons involved in memory storage throughout the lifespan (Meck and Williams 1997c, 1999). It is not known whether these effects persist into adulthood and old age in humans (Blusztajn et al. 2017).

\section{Choline call to action for the obstetrics and gynecology community}

Choline has been ranked last among common nutrients to recommend for a healthy diet, and only about $10 \%$ of health professionals indicate moderate familiarity with choline. Among obstetricians and gynecologists, only 6\% report they are likely to recommend choline-rich foods to pregnant women (StrategyOne Health Professionals Survey 2017). Our knowledge and understanding of choline have increased exponentially between the development of the DRIs in 1998 and today (Institute of Medicine 1998). Data from nationally representative surveys in the United States clearly demonstrate that suboptimal choline intakes are widespread in vulnerable subpopulations, including pregnant women (Wallace and Fulgoni 2017), women of childbearing age (Moshfegh 2018; Wallace and Fulgoni 2016, 2017), and vegetarians (Wallace 2015). In addition, a rapidly growing body of evidence relating inadequate maternal intakes to potential health consequences in the offspring warrants a need for health professionals to better communicate the need for choline-rich foods and supplementation, when appropriate. Choline seems to be a critical nutrient involved with neurocognitive development during gestation and lactation with lasting effects in children, although studies elucidating the dietary requirement for choline or whether it has lasting effects into adulthood are still in their infancy. Additional dose-response data by genotype are greatly needed to fully elucidate dietary requirements for choline before new DRIs can be developed; observational data will likely play a key role in this effort since ethical barriers prohibit clinical deprivation of any known essential nutrient in humans. Currently, the USDA is undertaking a "Birth to 24 Months and Pregnant Women Project" to support the Agricultural Act of 2014 (i.e., the Farm Bill) mandate for the 2020-2025 Dietary 
Guidelines for Americans to sizably expand past dietary guidance for pregnant women and, for the first time, guidance for infants younger than 24 months of age. The obstetrics and gynecology community must play a central role in these discussions so that science-based policies and consumer education strategies can be effectively implemented. Health professionals must advocate meeting the AIs for choline as there is a high likelihood that adverse neurological consequences due to suboptimal intakes will be confirmed in future human clinical research and because of the absence of harm of consuming choline at this level. Utilizing current government tools that assist Americans in selecting nutrient-dense foods that are within daily calorie goals is vital to helping to increase intake of all shortfall nutrients that promote cognitive development during the first thousand days postconception. Data indicate that increasing consumption of plant foods may offer many health benefits; however, this means consumers need to include more plant foods in the diet but not necessarily eliminate nutrientdense animal-derived foods such as eggs, lean meat, and low-fat/nonfat dairy. The food industry will be instrumental in developing new product innovations and formulations that are targeted to the needs of the individual subpopulations at risk.

\section{Acknowledgments}

The authors thank Ms. Christina West for her assistance in formatting and copyediting the manuscript.

\section{Declaration of interest}

TCW, JKB, MAC, and SHZ disclose research grant funding, scientific consulting or writing fees, travel reimbursement, and speaker honoraria from various food companies and commodity boards with an interest in choline. KCK is a graduate research assistant to MAC and has no direct conflict of interest to disclose.

\section{Funding}

The authors did not receive a financial incentive for the development of this manuscript.

\section{About the authors}

Taylor C. Wallace, PhD, CFS, FACN is the principal and CEO at the Think Healthy Group, Inc. and is an adjunct professor in the Department of Nutrition and Food Studies at George Mason University.

Jan Krzysztof Blusztajn, $\mathrm{PhD}$ is a professor in the Department of Pathology and Laboratory Medicine at Boston University School of Medicine.

Marie A. Caudill, $\mathrm{PhD}, \mathrm{RD}$ is a professor in the Division of Nutritional Sciences at Cornell University.

Kevin C. Klatt, $\mathrm{PhD}$ is a postdoctoral associate at the Baylor College of Medicine Children's Nutrition Research Center. 
Steven H. Zeisel, $\mathrm{MD}, \mathrm{PhD}$ is the director of the University of North Carolina Nutrition Research Institute, the director of the University of North Carolina Obesity Research Center, and a professor in the Department of Nutrition at the University of North Carolina.

\section{References}

Adeyemo O, Jeyakumar H. 1993. Plasma progesterone, estradiol-17 beta and testosterone in maternal and cord blood, and maternal human chorionic gonadotropin at parturition. Afr J Med Med Sci. 22:55-60.

Ash JA, Velazquez R, Kelley CM, Powers BE, Ginsberg SD, Mufson EJ, Strupp BJ. 2014. Maternal choline supplementation improves spatial mapping and increases basal forebrain cholinergic neuron number and size in aged Ts65Dn mice. Neurobiol Dis. 70:32-42. doi:10.1016/j. nbd.2014.06.001.

Bahnfleth C, Canfield R, Nevins J, Caudill M, Strupp B. 2019. Prenatal choline supplementation improves child color-location memory task performance at $7 \mathrm{y}$ of age (FS05-01-19). Curr Dev Nutr. 3. https://academic.oup.com/cdn/article/3/Supplement_1/nzz052.FS05-01-19/ 5517937? searchresult $=1$

Berg S. 2017. AMA backs global health experts in calling infertility a disease. AMA Wire [accessed 2019 July 22]. https://wire.ama-assn.org/ama-news/ama-backs-global-health-expertscalling-infertility-disease.

Blusztajn JK, Slack BE, Mellott TJ. 2017. Neuroprotective actions of dietary choline. Nutrients. 9: E815.

Boeke CE, Gillman MW, Hughes MD, Rifas-Shiman SL, Villamor E, Oken E. 2013. Choline intake during pregnancy and child cognition at age 7 years. Am J Epidemiol. 177(12):1338-47. doi:10.1093/aje/kws395.

Boyd WD, Graham-White J, Blackwood G, Glen I, McQueen J. 1977. Clinical effects of choline in Alzheimer senile dementia. Lancet. 2:711. doi:10.1016/S0140-6736(77)90517-7.

Buchman AL, Ament ME, Sohel M, Dubin M, Jenden DJ, Roch M, Pownall H, Farley W, Awal M, Ahn C. 2001. Choline deficiency causes reversible hepatic abnormalities in patients receiving parenteral nutrition: proof of a human choline requirement: a placebo-controlled trial. JPEN J Parenter Enteral Nutr. 25(5):260-8. doi:10.1177/0148607101025005260.

Buhusi CV, Lamoureux JA, Meck WH. 2008. Prenatal choline supplementation increases sensitivity to contextual processing of temporal information. Brain Res. 1237:204-13. doi:10.1016/j. brainres.2008.08.072.

Carmichael SL, Yang W, Shaw GM. 2010. Periconceptional nutrient intakes and risks of neural tube defects in California. Birth Defects Res A Clin Mol Teratol. 88(8):670-8. doi:10.1002/ bdra.20675.

Caudill MA, Strupp BJ, Muscalu L, Nevins JEH, Canfield RL. 2018. Maternal choline supplementation during the third trimester of pregnancy improves infant information processing speed: a randomized, double-blind, controlled feeding study. FASEB J. 32(4):2172-80. doi:10.1096/fj. 201700692RR.

Cermak JM, Blusztajn JK, Meck WH, Williams CL, Fitzgerald CM, Rosene DL, Loy R. 1999. Prenatal availability of choline alters the development of acetylcholinesterase in the rat hippocampus. Dev Neurosci. 21(2):94-104. doi:10.1159/000017371.

Cheatham CL, Goldman BD, Fischer LM, da Costa KA, Reznick JS, Zeisel SH. 2012. Phosphatidylcholine supplementation in pregnant women consuming moderate-choline diets does not enhance infant cognitive function: a randomized, double-blind, placebo-controlled trial. Am J Clin Nutr. 96(6):1465-72. doi:10.3945/ajcn.112.037184.

Cho CE, Taesuwan S, Malysheva OV, Bender E, Tulchinsky NF, Yan J, Sutter JL, Caudill MA. 2017. Trimethylamine-N-oxide (TMAO) response to animal source foods varies among healthy young men and is influenced by their gut microbiota composition: a randomized controlled trial. Mol Nutr Food Res. 61(1):1600324. doi:10.1002/mnfr.201600324. 
Cole LK, Vance JE, Vance DE. 2012. Phosphatidylcholine biosynthesis and lipoprotein metabolism. Biochim Biophys Acta. 1821(5):754-61. doi:10.1016/j.bbalip.2011.09.009.

Coles CD, Kable JA, Keen CL, Jones KL, Wertelecki W, Granovska IV, Pashtepa AO, Chambers CD. 2015. Dose and timing of prenatal alcohol exposure and maternal nutritional supplements: developmental effects on 6-month-old infants. Matern Child Health J. 19(12):2605-14. doi:10. 1007/s10995-015-1779-x.

Craig SA. 2004. Betaine in human nutrition. Am J Clin Nutr. 80(3):539-49. doi:10.1093/ajcn/80. 3.539 .

da Costa KA, Badea M, Fischer LM, Zeisel SH. 2004. Elevated serum creatine phosphokinase in choline-deficient humans: mechanistic studies in C2C12 mouse myoblasts. Am J Clin Nutr. 80(1):163-70. doi:10.1093/ajen/80.1.163.

da Costa KA, Niculescu MD, Craciunescu CN, Fischer LM, Zeisel SH. 2006. Choline deficiency increases lymphocyte apoptosis and DNA damage in humans. Am J Clin Nutr. 84(1):88-94. doi:10.1093/ajen/84.1.88.

Davison JM, Mellott TJ, Kovacheva VP, Blusztajn JK. 2009. Gestational choline supply regulates methylation of histone H3, expression of histone methyltransferases G9a (Kmt1c) and Suv39h1 (Kmtla), and DNA methylation of their genes in rat fetal liver and brain. J Biol Chem. 284(4): 1982-9. doi:10.1074/jbc.M807651200.

Dilger RN, Garrow TA, Baker DH. 2007. Betaine can partially spare choline in chicks but only when added to diets containing a minimal level of choline. J Nutr. 137(10):2224-8. doi:10. 1093/jn/137.10.2224.

Egger G, Liang G, Aparicio A, Jones PA. 2004. Epigenetics in human disease and prospects for epigenetic therapy. Nature. 429(6990):457-63. doi:10.1038/nature02625.

Emmert JL, Baker DH. 1997. A chick bioassay approach for determining the bioavailable choline concentration in normal and overheated soybean meal, canola meal and peanut meal. J Nutr. 127(5):745-52. doi:10.1093/jn/127.5.745.

European Food Safety Authority Nutrition Dietetics and Allergies Panel. 2016. Scientific opinion on dietary reference values for choline. EFSA J. 14:4484.

Falony G, Vieira-Silva S, Raes J. 2015. Microbiology meets big data: the case of gut microbiotaderived trimethylamine. Annu Rev Microbiol. 69(1):305-21. doi:10.1146/annurev-micro091014-104422.

Fischer LM, daCosta KA, Kwock L, Stewart PW, Lu T-S, Stabler SP, Allen RH, Zeisel SH. 2007. Sex and menopausal status influence human dietary requirements for the nutrient choline. Am J Clin Nutr. 85(5):1275-85. doi:10.1093/ajcn/85.5.1275.

Fisher MC, Zeisel SH, Mar MH, Sadler TW. 2001. Inhibitors of choline uptake and metabolism cause developmental abnormalities in neurulating mouse embryos. Teratology. 64(2):114-22. doi:10.1002/tera.1053.

Fisher MC, Zeisel SH, Mar MH, Sadler TW. 2002. Perturbations in choline metabolism cause neural tube defects in mouse embryos in vitro. FASEB J. 16(6):619-21. doi:10.1096/fj.010564fje.

Ganz A, Cohen V, Swersky C, Stover J, Vitiello G, Lovesky J, Chuang J, Shields K, Fomin V, Lopez Y, et al. 2017. Genetic variation in choline-metabolizing enzymes alters choline metabolism in young women consuming choline intakes meeting current recommendations. Int J Mol Sci. 18(2):252. doi:10.3390/ijms18020252.

Ganz AB, Klatt KC, Caudill MA. 2017. Common genetic variants alter metabolism and influence dietary choline requirements. Nutrients. 9(8):837. doi:10.3390/nu9080837.

Ganz AB, Shields K, Fomin VG, Lopez YS, Mohan S, Lovesky J, Chuang JC, Ganti A, Carrier B, Yan J, et al. 2016. Genetic impairments in folate enzymes increase dependence on dietary choline for phosphatidylcholine production at the expense of betaine synthesis. FASEB J. 30(10): 3321-33. doi:10.1096/fj.201500138RR.

Gelenberg AJ, Doller-Wojcik JC, Growdon JH. 1979. Choline and lecithin in the treatment of tardive dyskinesia: preliminary results from a pilot study. Am J Psychiatry. 136:772-6.

Glenn MJ, Kirby ED, Gibson EM, Wong-Goodrich SJ, Mellott TJ, Blusztajn JK, Williams CL. 2008. Age-related declines in exploratory behavior and markers of hippocampal plasticity are 
attenuated by prenatal choline supplementation in rats. Brain Res. 1237:110-23. doi:10.1016/j. brainres.2008.08.049.

Growdon JH, Cohen EL, Wurtman RJ. 1977. Huntington's disease: clinical and chemical effects of choline administration. Ann Neurol. 1(5):418-22. doi:10.1002/ana.410010503.

Hendricks KA, Simpson JS, Larsen RD. 1999. Neural tube defects along the Texas-Mexico border, 1993-1995. Am J Epidemiol. 149(12):1119-27. doi:10.1093/oxfordjournals.aje.a009766.

Hollenbeck CB. 2012. An introduction to the nutrition and metabolism of choline. Cent Nerv Syst Agents Med Chem. 12(2):100-13.

Holmes GL, Yang Y, Liu Z, Cermak JM, Sarkisian MR, Stafstrom CE, Neill JC, Blusztajn JK. 2002. Seizure-induced memory impairment is reduced by choline supplementation before or after status epilepticus. Epilepsy Res. 48(1-2):3-13. doi:10.1016/S0920-1211(01)00321-7.

Institute of Medicine. 1998. Dietary reference intakes: thiamin, riboflavin, niacin, vitamin B6, folate, vitamin B12, pantothenic acid, biotin, and choline. Washington (DC): National Academies Press.

Jiang X, Bar HY, Yan J, Jones S, Brannon PM, West AA, Perry CA, Ganti A, Pressman E, Devapatla S, et al. 2012. A higher maternal choline intake among third-trimester pregnant women lowers placental and circulating concentrations of the antiangiogenic factor fms-like tyrosine kinase-1 (sFLT1). FASEB J. 27(3):1245-53. doi:10.1096/fj.12-221648.

Jiang X, Jones S, Andrew BY, Ganti A, Malysheva OV, Giallourou N, Brannon PM, Roberson MS, Caudill MA. 2014. Choline inadequacy impairs trophoblast function and vascularization in cultured human placental trophoblasts. J Cell Physiol. 229(8):1016-27. doi:10.1002/jcp. 24526.

Jiang X, Yan J, West AA, Perry CA, Malysheva OV, Devapatla S, Pressman E, Vermeylen F, Caudill MA. 2012. Maternal choline intake alters the epigenetic state of fetal cortisol-regulating genes in humans. FASEB J. 26(8):3563-74. doi:10.1096/fj.12-207894.

Kable JA, Coles CD, Keen CL, Uriu-Adams JY, Jones KL, Yevtushok L, Kulikovsky Y, Wertelecki W, Pedersen TL, Chambers CD. 2015. The impact of micronutrient supplementation in alcohol-exposed pregnancies on information processing skills in Ukrainian infants. Alcohol. 49(7): 647-56. doi:10.1016/j.alcohol.2015.08.005.

Kelley CM, Ash JA, Powers BE, Velazquez R, Alldred MJ, Ikonomovic MD, ... Mufson EJ. 2016. Effects of maternal choline supplementation on the septohippocampal cholinergic system in the Ts65Dn mouse model of Down syndrome. Curr Alzheimer Res. 13:84-96. doi:10.2174/ 1567205012666150921100515.

Kelley CM, Powers BE, Velazquez R, Ash JA, Ginsberg SD, Strupp BJ, Mufson EJ. 2014. Maternal choline supplementation differentially alters the basal forebrain cholinergic system of young-adult Ts65Dn and disomic mice. J Comp Neurol. 522(6):1390-410. doi:10.1002/cne. 23492.

Kempson SA, Montrose MH. 2004. Osmotic regulation of renal betaine transport: transcription and beyond. Pflugers Arch. 449:227-34.

Kohlmeier M, da Costa KA, Fischer LM, Zeisel SH. 2005. Genetic variation of folate-mediated one-carbon transfer pathway predicts susceptibility to choline deficiency in humans. Proc Natl Acad Sci USA. 102(44):16025-30. doi:10.1073/pnas.0504285102.

Kovacheva VP, Davison JM, Mellott TJ, Rogers AE, Yang S, O’Brien MJ, Blusztajn JK. 2009. Raising gestational choline intake alters gene expression in DMBA-evoked mammary tumors and prolongs survival. FASEB J. 23(4):1054-63. doi:10.1096/fj.08-122168.

Kovacheva VP, Mellott TJ, Davison JM, Wagner N, Lopez-Coviella I, Schnitzler AC, Blusztajn JK. 2007. Gestational choline deficiency causes global and Igf2 gene DNA hypermethylation by up-regulation of Dnmt1 expression. J Biol Chem. 282(43):31777-88. doi:10.1074/jbc. M705539200.

Kwan STC, King JH, Yan J, Jiang X, Wei E, Fomin VG, Roberson MS, Caudill MA. 2017. Maternal choline supplementation during murine pregnancy modulates placental markers of inflammation, apoptosis and vascularization in a fetal sex-dependent manner. Placenta. 53: 57-65. doi:10.1016/j.placenta.2017.03.019. 
Kwan STC, King JH, Yan J, Wang Z, Jiang X, Hutzler JS, Klein HR, Brenna JT, Roberson MS, Caudill MA. 2017. Maternal choline supplementation modulates placental nutrient transport and metabolism in late gestation of mouse pregnancy. J Nutr. 147:2083-92.

Kwan TS, King HJ, Grenier KJ, Yan J, Jiang X, Roberson SM, Caudill AM. 2018. Maternal choline supplementation during normal murine pregnancy alters the placental epigenome: results of an exploratory study. Nutrients. 10(4):417. doi:10.3390/nu10040417.

Lavery AM, Brender JD, Zhao H, Sweeney A, Felkner M, Suarez L, Canfield MA. 2014. Dietary intake of choline and neural tube defects in Mexican Americans. Birth Defects Res A Clin Mol Teratol. 100(6):463-71. doi:10.1002/bdra.23236.

Lawrence CM, Millac P, Stout GS, Ward JW. 1980. The use of choline chloride in ataxic disorders. J Neurol Neurosurg Psychiatry. 43(5):452-4. doi:10.1136/jnnp.43.5.452.

Ley RE, Backhed F, Turnbaugh P, Lozupone CA, Knight RD, Gordon JI. 2005. Obesity alters gut microbial ecology. Proc Natl Acad Sci USA. 102(31):11070-5. doi:10.1073/pnas.0504978102.

Li Z, Agellon LB, Vance DE. 2005. Phosphatidylcholine homeostasis and liver failure. J Biol Chem. 280(45):37798-802. doi:10.1074/jbc.M508575200.

Loy R, Heyer D, Williams CL, Meck WH. 1991. Choline-induced spatial memory facilitation correlates with altered distribution and morphology of septal neurons. Adv Exp Med Biol. 295: 373-82.

McCann JC, Hudes M, Ames BN. 2006. An overview of evidence for a causal relationship between dietary availability of choline during development and cognitive function in offspring. Neurosci Biobehav Rev. 30(5):696-712. doi:10.1016/j.neubiorev.2005.12.003.

Meck WH, Williams CL. 1997a. Characterization of the facilitative effects of perinatal choline supplementation on timing and temporal memory. Neuroreport. 8(13):2831-5. doi:10.1097/ 00001756-199709080-00005.

Meck WH, Williams CL. 1997b. Perinatal choline supplementation increases the threshold for chunking in spatial memory. Neuroreport. 8(14):3053-9. doi:10.1097/00001756-19970929000010 .

Meck WH, Williams CL. 1997c. Simultaneous temporal processing is sensitive to prenatal choline availability in mature and aged rats. Neuroreport. 8(14):3045-51. doi:10.1097/00001756199709290-00009.

Meck WH, Williams CL. 1999. Choline supplementation during prenatal development reduces proactive interference in spatial memory. Brain Res Dev Brain Res. 118(1-2):51-9. doi:10.1016/ S0165-3806(99)00105-4.

Meck WH, Williams CL, Cermak JM, Blusztajn JK. 2007. Developmental periods of choline sensitivity provide an ontogenetic mechanism for regulating memory capacity and age-related dementia. Front Integr Neurosci. 1:7.

Mills JL, Fan R, Brody LC, Liu A, Ueland PM, Wang Y, Kirke PN, Shane B, Molloy AM. 2014. Maternal choline concentrations during pregnancy and choline-related genetic variants as risk factors for neural tube defects. Am J Clin Nutr. 100(4):1069-74. doi:10.3945/ajcn.113.079319.

Moon J, Chen M, Gandhy SU, Strawderman M, Levitsky DA, Maclean KN, Strupp BJ. 2010. Perinatal choline supplementation improves cognitive functioning and emotion regulation in the Ts65Dn mouse model of Down syndrome. Behav Neurosci. 124(3):346-61. doi:10.1037/ a0019590.

Moshfegh AJ. 2018. Choline intake in the US. Paper presented at the 2018 Choline Summit, Washington, DC USA.

Nag N, Berger-Sweeney JE. 2007. Postnatal dietary choline supplementation alters behavior in a mouse model of Rett syndrome. Neurobiol Dis. 26(2):473-80. doi:10.1016/j.nbd.2007.02.003.

Nag N, Mellott TJ, Berger-Sweeney JE. 2008. Effects of postnatal dietary choline supplementation on motor regional brain volume and growth factor expression in a mouse model of Rett syndrome. Brain Res. 1237:101-9. doi:10.1016/j.brainres.2008.08.042.

Niculescu MD, da Costa KA, Fischer LM, Zeisel SH. 2007. Lymphocyte gene expression in subjects fed a low-choline diet differs between those who develop organ dysfunction and those who do not. Am J Clin Nutr. 86(1):230-9. doi:10.1093/ajcn/86.1.230. 
Otero NK, Thomas JD, Saski CA, Xia X, Kelly SJ. 2012. Choline supplementation and DNA methylation in the hippocampus and prefrontal cortex of rats exposed to alcohol during development. Alcohol Clin Exp Res. 36(10):1701-9. doi:10.1111/j.1530-0277.2012.01784.x.

Powers BE, Kelley CM, Velazquez R, Ash JA, Strawderman MS, Alldred MJ, Ginsberg SD, Mufson EJ, Strupp BJ. 2017. Maternal choline supplementation in a mouse model of Down syndrome: effects on attention and nucleus basalis/substantia innominata neuron morphology in adult offspring. Neuroscience. 340:501-14. doi:10.1016/j.neuroscience.2016.11.001.

Pyapali GK, Turner DA, Williams CL, Meck WH, Swartzwelder HS. 1998. Prenatal dietary choline supplementation decreases the threshold for induction of long-term potentiation in young adult rats. J Neurophysiol. 79(4):1790-6. doi:10.1152/jn.1998.79.4.1790.

Resseguie M, Song J, Niculescu MD, da Costa KA, Randall TA, Zeisel SH. 2007. Phosphatidylethanolamine N-methyltransferase (PEMT) gene expression is induced by estrogen in human and mouse primary hepatocytes. FASEB J. 21(10):2622-32. doi:10.1096/fj.07$8227 \mathrm{com}$.

Resseguie ME, da Costa KA, Galanko JA, Patel M, Davis IJ, Zeisel SH. 2011. Aberrant estrogen regulation of PEMT results in choline deficiency-associated liver dysfunction. J Biol Chem. 286(2):1649-58. doi:10.1074/jbc.M110.106922.

Ricceri L, De Filippis B, Fuso A, Laviola G. 2011. Cholinergic hypofunction in MeCP2-308 mice: beneficial neurobehavioural effects of neonatal choline supplementation. Behav Brain Res. 221(2):623-9. doi:10.1016/j.bbr.2011.03.051.

Ricceri L, De Filippis B, Laviola G. 2013. Rett syndrome treatment in mouse models: searching for effective targets and strategies. Neuropharmacology. 68:106-15. doi:10.1016/j.neuropharm. 2012.08.010.

Ross RG, Hunter SK, McCarthy L, Beuler J, Hutchison AK, Wagner BD, Leonard S, Stevens KE, Freedman R. 2013. Perinatal choline effects on neonatal pathophysiology related to later schizophrenia risk. Am J Psychiatry. 170(3):290-8. doi:10.1176/appi.ajp.2012.12070940.

Ryan SH, Williams JK, Thomas JD. 2008. Choline supplementation attenuates learning deficits associated with neonatal alcohol exposure in the rat: effects of varying the timing of choline administration. Brain Res. 1237:91-100. doi:10.1016/j.brainres.2008.08.048.

Sarda IR, Gorwill RH. 1976. Hormonal studies in pregnancy. I. Total unconjugated estrogens in maternal peripheral vein, cord vein, and cord artery serum at delivery. Am J Obstet Gynecol. 124(3):234-8.

Schneider RD, Thomas JD. 2016. Adolescent choline supplementation attenuates working memory deficits in rats exposed to alcohol during the third trimester equivalent. Alcohol Clin Exp Res. 40(4):897-905. doi:10.1111/acer.13021.

Schwarzenberg SJ, Georgieff MK. 2018. Advocacy for improving nutrition in the first 1000 days to support childhood development and adult health. Pediatrics. 141(2):e20173716. doi:10.1542/ peds.2017-3716.

Secades JJ, Lorenzo JL. 2006. Citicoline: pharmacological and clinical review, 2006 update. Methods Find Exp Clin Pharmacol. 28(Suppl B):1-56.

Shaw GM, Carmichael SL, Laurent C, Rasmussen SA. 2006. Maternal nutrient intakes and risk of orofacial clefts. Epidemiology. 17(3):285-91. doi:10.1097/01.ede.0000208348.30012.35.

Shaw GM, Carmichael SL, Yang W, Selvin S, Schaffer DM. 2004. Periconceptional dietary intake of choline and betaine and neural tube defects in offspring. Am J Epidemiol. 160(2):102-9. doi:10.1093/aje/kwh187.

Shaw GM, Finnell RH, Blom HJ, Carmichael SL, Vollset SE, Yang W, Ueland PM. 2009. Choline and risk of neural tube defects in a folate-fortified population. Epidemiology. 20(5):714-9. doi: 10.1097/EDE.0b013e3181ac9fe7.

Signore C, Ueland PM, Troendle J, Mills JL. 2008. Choline concentrations in human maternal and cord blood and intelligence at $5 \mathrm{y}$ of age. Am J Clin Nutr. 87(4):896-902. doi:10.1093/ ajcn/87.4.896.

Song J, da Costa KA, Fischer LM, Kohlmeier M, Kwock L, Wang S, Zeisel SH. 2005. Polymorphism of the PEMT gene and susceptibility to nonalcoholic fatty liver disease (NAFLD). FASEB J. 19(10):1266-71. doi:10.1096/fj.04-3580com. 
StrategyOne Health Professionals Survey. 2017. Online study among 252 health care professionals from Harris Interactive's Physicians and Specialty Health Professionals Panels. Sponsored by American Egg Board/Egg Nutrition Center [accessed 2019 Mar 19]. http://www.cholineinfo. org/healthcare_professionals/overview.asp.

Strupp BJ, Powers BE, Velazquez R, Ash JA, Kelley CM, Alldred MJ, ... Ginsberg SD. 2016. Maternal choline supplementation: a potential prenatal treatment for Down syndrome and Alzheimer's disease. Curr Alzheimer Res. 13:97-106. doi:10.2174/1567205012666150921100311.

Tees RC. 1999a. The influences of rearing environment and neonatal choline dietary supplementation on spatial learning and memory in adult rats. Behav Brain Res. 105(2):173-88. doi:10. 1016/S0166-4328(99)00074-1.

Tees RC. 1999b. The influences of sex, rearing environment, and neonatal choline dietary supplementation on spatial and nonspatial learning and memory in adult rats. Dev Psychobiol. 35(4): 328-42. doi:10.1002/(SICI)1098-2302(199912)35:4<328::AID-DEV7>3.0.CO;2-4.

Thomas JD, Biane JS, O’Bryan KA, O'Neill TM, Dominguez HD. 2007. Choline supplementation following third-trimester-equivalent alcohol exposure attenuates behavioral alterations in rats. Behav Neurosci. 121(1):120-30. doi:10.1037/0735-7044.121.1.120.

Thomas JD, La Fiette MH, Quinn VR, Riley EP. 2000. Neonatal choline supplementation ameliorates the effects of prenatal alcohol exposure on a discrimination learning task in rats. Neurotoxicol Teratol. 22(5):703-11. doi:10.1016/S0892-0362(00)00097-0.

Thomas JD, Tran TD. 2012. Choline supplementation mitigates trace, but not delay, eyeblink conditioning deficits in rats exposed to alcohol during development. Hippocampus. 22(3): 619-30. doi:10.1002/hipo.20925.

U.S. Department of Agriculture. 2008. USDA database for the choline content of common foods: Release 2 [accessed 2019 July 22]. https://www.ars.usda.gov/ARSUserFiles/80400525/Data/ Choline/Choln02.pdf.

U.S. Department of Health and Human Services, \& U.S. Department of Agriculture. 2015. 2015-2020 dietary guidelines for Americans (8th ed.). Retrieved from https://health.gov/dietaryguidelines/2015/guidelines/.

U.S. Food and Drug Administration. 2017. Regulations and information on the manufacture and distribution of infant formula [accessed 2019 Jul 22]. Retrieved from https://www.fda.gov/ Food/GuidanceRegulation/GuidanceDocumentsRegulatoryInformation/InfantFormula/ ucm136118.htm.

Velazquez R, Ash JA, Powers BE, Kelley CM, Strawderman M, Luscher ZI, Ginsberg SD, Mufson EJ, Strupp BJ. 2013. Maternal choline supplementation improves spatial learning and adult hippocampal neurogenesis in the Ts65Dn mouse model of Down syndrome. Neurobiol Dis. 58: 92-101. doi:10.1016/j.nbd.2013.04.016.

Villamor E, Rifas-Shiman SL, Gillman MW, Oken E. 2012. Maternal intake of methyl-donor nutrients and child cognition at 3 years of age. Paediatr Perinat Epidemiol. 26(4):328-35. doi: 10.1111/j.1365-3016.2012.01264.x.

Wallace TC. 2015. Choline in foods, functional foods and dietary supplements. Paper presented at the Institute of Food Technologists Annual Meeting, Chicago, IL.

Wallace TC. 2018. A comprehensive review of eggs, choline, and lutein on cognition across the life-span. J Am Coll Nutr. 37(4):269-285. doi:10.1080/07315724.2017.1423248.

Wallace TC, Fulgoni VL. 2017. Usual choline intakes are associated with egg and protein food consumption in the United States. Nutrients. 9(8):839.

Wallace TC, Fulgoni VL, 3rd. 2016. Assessment of total choline intakes in the United States. J Am Coll Nutr. 35(2):108-12. doi:10.1080/07315724.2015.1080127.

Waterland RA, Jirtle RL. 2004. Early nutrition, epigenetic changes at transposons and imprinted genes, and enhanced susceptibility to adult chronic diseases. Nutrition. 20(1):63-8. doi:10. 1016/j.nut.2003.09.011.

Williams CL, Meck WH, Heyer DD, Loy R. 1998. Hypertrophy of basal forebrain neurons and enhanced visuospatial memory in perinatally choline-supplemented rats. Brain Res. 794(2): 225-38. doi:10.1016/S0006-8993(98)00229-7. 
Wong-Goodrich SJ, Glenn MJ, Mellott TJ, Liu YB, Blusztajn JK, Williams CL. 2011. Water maze experience and prenatal choline supplementation differentially promote long-term hippocampal recovery from seizures in adulthood. Hippocampus. 21(6):584-608. doi:10.1002/hipo.20783.

Wu BT, Dyer RA, King DJ, Richardson KJ, Innis SM. 2012. Early second trimester maternal plasma choline and betaine are related to measures of early cognitive development in term infants. PLoS One. 7(8):e43448. doi:10.1371/journal.pone.0043448.

Yan J, Jiang X, West AA, Perry CA, Malysheva OV, Brenna JT, Stabler SP, Allen RH, Gregory JF, Caudill MA. 2013. Pregnancy alters choline dynamics: results of a randomized trial using stable isotope methodology in pregnant and nonpregnant women. Am J Clin Nutr. 98(6): 1459-67. doi:10.3945/ajen.113.066092.

Yan J, Jiang X, West AA, Perry CA, Malysheva OV, Devapatla S, Pressman E, Vermeylen F, Stabler SP, Allen RH, Caudill MA. 2012. Maternal choline intake modulates maternal and fetal biomarkers of choline metabolism in humans. Am J Clin Nutr. 95(5):1060-71. doi:10.3945/ ajcn.111.022772.

Yang Y, Liu Z, Cermak JM, Tandon P, Sarkisian MR, Stafstrom CE, Neill JC, Blusztajn JK, Holmes GL. 2000. Protective effects of prenatal choline supplementation on seizure-induced memory impairment. J Neurosci. 20(22):Rc109. doi:10.1523/JNEUROSCI.20-22-j0006.2000.

Yao ZM, Vance DE. 1988. The active synthesis of phosphatidylcholine is required for very low density lipoprotein secretion from rat hepatocytes. J Biol Chem. 263:2998-3004.

Zeisel SH. 2000. Choline: an essential nutrient for humans. Nutrition. 16(7-8):669-71.

Zeisel SH. 2012. Dietary choline deficiency causes DNA strand breaks and alters epigenetic marks on DNA and histones. Mutat Res. 733(1-2):34-8. doi:10.1016/j.mrfmmm.2011.10.008.

Zeisel SH, Caudill MA. 2010. Choline. Adv Nutr. 1(1):46-8. doi:10.3945/an.110.1010.

Zeisel SH, da Costa KA. 2009. Choline: an essential nutrient for public health. Nutr Rev. 67(11): 615-23. doi:10.1111/j.1753-4887.2009.00246.x.

Zeisel SH, Da Costa KA, Franklin PD, Alexander EA, Lamont JT, Sheard NF, Beiser A. 1991. Choline, an essential nutrient for humans. FASEB J. 5(7):2093-8. 